\title{
Use of endoscopic ultrasound for pancreatic cancer from 2000 to 2016
}

\section{두)(우우}

\section{Authors}

Sheila D. Rustgi ${ }^{1}$, Haley M. Zylberberg², Sunil Amin ${ }^{3}$, Anne Aronson ${ }^{4}$, Satish Nagula ${ }^{2,4}$, Christopher J. DiMaio ${ }^{2,4}$, Nikhil A. Kumta 2,4 , Aimee L. Lucas 2,4

\section{Institutions}

1 Division of Digestive and Liver Diseases, Columbia University Irving Medical Center, New York, New York, United States

2 Department of Medicine, Icahn School of Medicine at Mount Sinai, New York, NY

3 Division of Gastroenterology, University of Miami Leonard M. Miller School of Medicine, Miami, Florida, United States

4 Henry D Janowitz Division of Gastroenterology, Icahn School of Medicine at Mount Sinai, New York, New York, United States

submitted 11.5.2021

accepted after revision $\quad 10.8 .2021$

Bibliography

Endosc Int Open 2022; 10: E19-E29

DOI 10.1055/a-1608-0856

ISSN 2364-3722

(C) 2022. The Author(s).

This is an open access article published by Thieme under the terms of the Creative Commons Attribution-NonDerivative-NonCommercial License, permitting copying and reproduction so long as the original work is given appropriate credit. Contents may not be used for commercial purposes, or adapted, remixed, transformed or built upon. (https://creativecommons.org/licenses/by-nc-nd/4.0/)

Georg Thieme Verlag KG, Rüdigerstraße 14,

70469 Stuttgart, Germany

\section{Corresponding author}

Aimee L. Lucas, MD, MS, Associate Professor of Medicine, Division of Gastroenterology, Icahn School of Medicine at Mount Sinai, One Gustave L. Levy Place, Box 1069, New York, NY 10029, United States

Fax: +1-646-537-8647

aimee.lucas@mssm.edu $\bigoplus$ Supplementary material is available under
https://doi.org/10.1055/a-1608-0856

\section{ABSTRACT}

Background and study aims Pancreatic cancer (PC) is the fourth most common cause of cancer death in the United States. Previous studies have suggested a survival benefit for endoscopic ultrasound (EUS), an important tool for diagnosis and staging of PC. This study aims to describe EUS use over time and identify factors associated with EUS use and its impact on survival.

Patients and methods This was a retrospective review of the Surveillance, Epidemiology and End Results (SEER) database linked with Medicare claims. EUS use, clinical and demographic characteristics were evaluated. Chi-squared analysis, Cochran-Armitage test for trend, and logistic regression were used to identify associations between sociodemographic and clinical factors and EUS.Kaplan-Meier and Cox proportional hazard ratios were used for survival analysis.

Results EUS use rose during the time period, from $7.4 \%$ of patients in 2000 to $32.4 \%$ in 2015 . Patient diversity increased, with a rising share of older, non-White patients with higher Charlson comorbidity scores. Both clinical (receipt of other therapies, PC stage) and nonclinical factors (region of country, year of diagnosis) were associated with receipt of EUS. While EUS was associated with a survival improvement early in the study period, this effect did not persist for PC patients diagnosed in 2012 to 2015 (median survival 3 month \pm standard deviation [SD] 9.8 months without vs. 4 months \pm SD 8 months with EUS).

Conclusions Our data support previous studies, which suggest a survival benefit for EUS when it was infrequently used, but finds that benefit was attenuated as EUS became more widely available. 


\section{Introduction}

Pancreatic cancer (PC) was the fourth most common cause of cancer death in 2020 [1]. In contrast with most other types of cancer in the United States, survival from PC is not improving, in part because of late stage at time of diagnosis [1]. The diagnosis can be challenging but endoscopic ultrasound (EUS) is an important tool for diagnosis, tissue acquisition and staging of disease [2,3].

Previous studies suggest a survival benefit for EUS [4]; however, since this is a diagnostic and not therapeutic procedure, there must be other factors such as access to care or improved staging of disease that lead to this benefit. Because of the poor prognosis, any efforts to optimize current practice to improve outcomes for these patients may have significant impact. Therefore, it is important to understand how health care is delivered for these patients. Indeed, studies show that non-clinical factors, including patient race, age, and geographic location, impact utilization of cancer-directed therapies, including endoscopic retrograde cholangiopancreatography (ERCP) and surgery [5-7].

Use of EUS has been increasing over the past 20 years [8]. Increasingly, more physicians have become trained in this procedure, either during fellowship, through advanced courses, or during a fourth year of fellowship. In 2012, the American Society for Gastrointestinal Endoscopy (ASGE) created a formal match process for a fourth-year fellowship. More providers trained in this technique became available outside expert centers to provide it as part of PC care. This is reflected in the ASGE guidelines as well, which changed from favoring ERCP in 2005 [9] for diagnosis of PC to favoring EUS by 2016 [2].

The aim of this study was to describe the use of EUS over time and identify non-clinical factors associated with use of EUS and its impact on survival. We hypothesized that EUS would become increasingly available over the time period studied and the survival benefit described in earlier reports would disappear as it was used more widely.

\section{Patients and methods}

\section{Patient selection and treatment}

The Surveillance, Epidemiology and End Results (SEER) database of the National Cancer Institute $(\mathrm{NCl})$ is a national cancer registry with cancer incidence and survival data [10]. This database is linked with a patient's Medicare claims from time of Medicare eligibility (age 65 and older) until death. Patients with primary PC diagnosed between 2000 and 2015 were identified. Patients with more than one primary cancer were excluded to eliminate the effect of synchronous or metachronous cancers on overall survival [11]. Individuals with Medicare fee-forservice only were included; Medicare managed care and secondary insurance were excluded for incomplete claims [12]. Patient age was limited to those 65 and older because this is the age of eligibility for Medicare coverage in the United States.

Adenocarcinoma was selected for using the International Classification of Diseases for Oncology, Second Edition (ICD-O2,1992 ) histology codes $8000,8010,8140,8500,8550$, and
8560. Sociodemographic information was obtained from both the SEER and Medicare-linked databases. Patient comorbid conditions, such as cardiovascular disease and chronic kidney disease (CKD), were controlled for using the Deyo adaption of the Charlson comorbidity index before diagnosis with PC [1315]. Patient stage was based on the SEER historical stage, since the American Joint Committee on Cancer (AJCC) stage data was not available for the years 2000-2003. SEER stage is listed as localized, regional, and distant disease, which is different from the more widely used AJCC stage data [16]. Localized means the tumor is limited to the organ of origin; regional means the tumor has extended beyond the organ of origin either directly or into lymph nodes; and distant which includes metastases to other parts of the body [17]. Both inpatient and outpatient hospital claims (Medicare Provider Analysis and Review, Outpatient Standard Analytical File) as well as diagnoses on claims submitted by individual physicians (Carrier file) were included $[12,15]$.

EUS was identified using ICD-9 codes, ICD-10 and the Healthcare Common Procedure Coding System (HCPCS) codes. EUS was included as associated with the PC if it was performed within 3 months before or after diagnosis. There may be a delay in diagnosis by claims dates, therefore, 3 months was used as in other studies [4]. Surgery, chemotherapy, and radiation were identified from claims data using ICD-9, ICD-10, and HCPCS codes [18].

\section{Study outcome}

The primary outcome of the study was trends in use of EUS over time. Survival times were calculated as the period from date of diagnosis of PC to the date of death. Subjects alive on December 15, 2015 were censored.

\section{Statistical analysis}

Demographic characteristics were compared using chi-squared analyses for categorical variables and Student $t$-test for continuous variables. Cochran-Armitage test for trend was performed to evaluate differences in use of EUS over time. Multivariable logistic regression was performed to identify factors associated with receipt of EUS. Survival analysis was performed using both univariable and multivariable analysis. Cox Proportional Hazard modeling was then employed to adjust for confounding factors including age, marital status, symptoms, and Charlson comorbidity scores. Alpha level of 0.05 was used to determine statistical significance. All statistical analyses were performed using SAS version 9.3 and 9.4 (Cary, North Carolina, United States). The study was approved by both the Institutional Review Board and the $\mathrm{NCl}$.

\section{Results}

\section{Cohort description}

Of the 42,162 patients diagnosed with PC from 2000 to 2016 in the cohort, more than one in five $(9,948$ or $23.6 \%)$ received EUS ( $\triangleright$ Table 1). Furthermore, the use of EUS increased during this time period. In the first 4 years, $11.2 \%$ of patients received EUS, whereas by the last 4 years, this share had increased to $30.2 \%$ of all patients ( Table $\mathbf{1}$ ). 
- Table 1 Sociodemographic and clinical characteristics of patients with pancreatic cancer by receipt of EUS, 2000 to 2016.

\begin{tabular}{|c|c|c|c|c|c|c|}
\hline & Total & & $\begin{array}{l}\text { Received EUS } \\
\text { per diagnosis }\end{array}$ & & & \\
\hline & $\mathbf{n}$ & $\%$ & $\mathbf{n}$ & $\%$ of total who received EUS & $\%$ of total population & $P$ value \\
\hline Total & 42,162 & $100.0 \%$ & 9,948 & $100.0 \%$ & $23.6 \%$ & $<0.01$ \\
\hline \multicolumn{6}{|l|}{ Year } & $<0.01$ \\
\hline 2000-2003 & 10,356 & $24.6 \%$ & 1,155 & $11.6 \%$ & $11.2 \%$ & \\
\hline 2004-2007 & 10,977 & $26.0 \%$ & 2,323 & $23.4 \%$ & $21.2 \%$ & \\
\hline 2008-2011 & 10,479 & $24.9 \%$ & 3,349 & $33.7 \%$ & $32.0 \%$ & \\
\hline 2012-2015 & 10,350 & $24.5 \%$ & 3,121 & $31.4 \%$ & $30.2 \%$ & \\
\hline \multicolumn{6}{|l|}{ Sex } & $<0.01$ \\
\hline Male & 18,388 & $43.6 \%$ & 4,476 & $45.0 \%$ & $24.3 \%$ & \\
\hline Female & 23,774 & $56.4 \%$ & 5,472 & $55.0 \%$ & $23.0 \%$ & \\
\hline Age & & & & & & $<0.01$ \\
\hline $66-75$ & 18,147 & $43.0 \%$ & 5,054 & $50.8 \%$ & $27.9 \%$ & \\
\hline $76+$ & 24,015 & $57.0 \%$ & 4,894 & $49.2 \%$ & $20.4 \%$ & \\
\hline \multicolumn{6}{|l|}{ Ethnicity } & $<0.01$ \\
\hline White & 35,492 & $84.2 \%$ & 8,545 & $85.9 \%$ & $24.1 \%$ & \\
\hline Black & 4,227 & $10.0 \%$ & 802 & $8.1 \%$ & $19.0 \%$ & \\
\hline American Indian & 179 & $0.4 \%$ & 29 & $0.3 \%$ & $16.2 \%$ & \\
\hline Asian/Pacific Islander & 2,187 & $5.2 \%$ & 542 & $5.4 \%$ & $24.8 \%$ & \\
\hline \multicolumn{6}{|l|}{ Married } & $<0.01$ \\
\hline Yes & 20,638 & $48.9 \%$ & 5,457 & $54.9 \%$ & $26.4 \%$ & \\
\hline No & 21,524 & $51.1 \%$ & 4,491 & $45.1 \%$ & $20.9 \%$ & \\
\hline \multicolumn{6}{|l|}{ Metro Area } & $<0.01$ \\
\hline Metro & 35,344 & $83.8 \%$ & 8,534 & $85.8 \%$ & $24.1 \%$ & \\
\hline Non-metro & 6,815 & $16.2 \%$ & 1,413 & $14.2 \%$ & $20.7 \%$ & \\
\hline \multicolumn{6}{|l|}{ Region } & $<0.01$ \\
\hline Northeast & 9,213 & $21.9 \%$ & 2,302 & $23.1 \%$ & $25.0 \%$ & \\
\hline Southeast & 10,390 & $24.6 \%$ & 1,981 & $19.9 \%$ & $19.1 \%$ & \\
\hline Midwest & 5,463 & $13.0 \%$ & 1,252 & $12.6 \%$ & $22.9 \%$ & \\
\hline West coast & 17,096 & $40.5 \%$ & 4,413 & $44.4 \%$ & $25.8 \%$ & \\
\hline \multicolumn{6}{|l|}{ Income } & $<0.01$ \\
\hline High income & 10,377 & $24.6 \%$ & 2,888 & $29.0 \%$ & $27.8 \%$ & \\
\hline Low income & 30,941 & $73.4 \%$ & 6,886 & $69.2 \%$ & $22.3 \%$ & \\
\hline \multicolumn{6}{|l|}{ Education } & $<0.01$ \\
\hline High education & 10,318 & $24.5 \%$ & 2,056 & $20.7 \%$ & $19.9 \%$ & \\
\hline Low education & 31,006 & $73.5 \%$ & 7,723 & $77.6 \%$ & $24.9 \%$ & \\
\hline \multicolumn{6}{|l|}{ SEER historic stage } & $<0.01$ \\
\hline Local & 4,100 & $9.7 \%$ & 1,226 & $12.3 \%$ & $29.9 \%$ & \\
\hline Regional & 11,789 & $28.0 \%$ & 4,688 & $47.1 \%$ & $39.8 \%$ & \\
\hline Distant & 21,998 & $52.2 \%$ & 3,450 & $34.7 \%$ & $15.7 \%$ & \\
\hline
\end{tabular}


- Table 1 (Continuation)

\begin{tabular}{|c|c|c|c|c|c|c|}
\hline & Total & & $\begin{array}{l}\text { Received EUS } \\
\text { per diagnosis }\end{array}$ & & & \\
\hline & $\mathbf{n}$ & $\%$ & $\mathbf{n}$ & $\%$ of total who received EUS & $\%$ of total population & $P$ value \\
\hline \multicolumn{6}{|c|}{ Charlson Comorbidity Score } & 0.03 \\
\hline $0-1$ & 26,850 & $63.7 \%$ & 6,355 & $63.9 \%$ & $23.7 \%$ & \\
\hline \multirow[t]{2}{*}{$2+$} & 9,833 & $23.3 \%$ & 2,218 & $22.3 \%$ & $22.6 \%$ & \\
\hline & & & & & & $<0.01$ \\
\hline Head of Pancreas & 21,382 & $50.7 \%$ & 6,528 & $65.6 \%$ & $30.5 \%$ & \\
\hline Body/tail & 20,780 & $49.3 \%$ & 3,420 & $34.4 \%$ & $16.5 \%$ & \\
\hline $\begin{array}{l}\text { Diagnosis confirmed } \\
\text { with tissue }\end{array}$ & 32,760 & $77.7 \%$ & 9,312 & $93.6 \%$ & $28.4 \%$ & $<0.01$ \\
\hline ERCP & 18,024 & $42.7 \%$ & 5,956 & $59.9 \%$ & $33.0 \%$ & $<0.01$ \\
\hline Chemotherapy & 17,444 & $41.4 \%$ & 5,658 & $56.9 \%$ & $32.4 \%$ & $<0.01$ \\
\hline Radiation & 8,680 & $20.6 \%$ & 2,983 & $30.0 \%$ & $34.4 \%$ & $<0.01$ \\
\hline Surgery & 5,148 & $12.2 \%$ & 1,976 & $19.9 \%$ & $38.4 \%$ & $<0.01$ \\
\hline
\end{tabular}

There were several differences between patients who received EUS and those who did not ( Table 1). Sociodemographic factors associated with receipt of EUS included male sex, younger age, race, marital status, living in metropolitan areas, and region of the country.

Clinical factors including cancer location in the head of the pancreas and stage were associated with EUS use. Patients with fewer comorbid conditions as measured by the Charlson comorbidity score also received EUS more often. Patients who underwent other cancer-directed therapies, including ERCP, surgery, chemotherapy, and radiation, were more likely to get EUS. Among the 32,760 patients who had their diagnosis confirmed with tissue diagnosis, 9,312 (28.4\%) had EUS.

\section{Trends over time}

In 2000, $7.4 \%$ of patients received an EUS; by 2015 that number had increased to $32.4 \%$ of patients (Cochran Armitage test, $P<$ 0.01 , Fig. 1a). The share of patients by each characteristic in - Table 1 receiving EUS increased significantly over time. For example, non-White patients underwent EUS less often than other groups: in 2000 , only $4.7 \%$ of non-White patients received EUS and this share rose to $30.8 \%$ of non-White patients by 2015. In contrast, patients with locoregional disease underwent EUS most often. In 2000, $13.7 \%$ of patients with locoregional disease underwent EUS and this share rose to $45.5 \%$ in 2015.

However, as the overall number of EUS performed increased over time, the patient characteristics became more diverse. Among those receiving EUS, the share of older patients, nonWhite patients, not married patients, and patients in the Southeast, Midwest and West Coast increased annually over the time period (Supplemental Table, > Fig. 2a). The distribution by sex

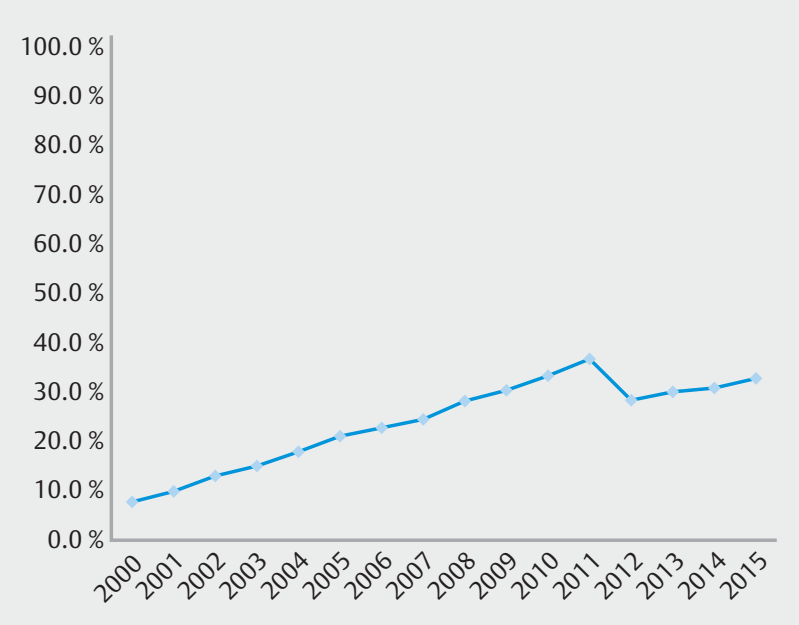

- Fig. 1 Share of patients with pancreatic cancer who received endoscopic ultrasound by year of diagnosis

and residence in a metropolitan area or the Northeast United States was not significantly different over time.

Similarly, more patients with higher Charlson comorbidity scores $(2+)$ and patients with metastatic disease were among those who underwent EUS over time ( $\mathbf{F i g . 2 b}$ and $>$ Fig. $\mathbf{2 c}$, $P<0.01)$. The total number of patients undergoing both EUS and treatment (surgery, chemotherapy, or radiation) increased over time (all $P<0.01$ ). However, the share of patients who received EUS as well as other cancer-directed therapy, including radiation and surgery, decreased over time, meaning more pa- 


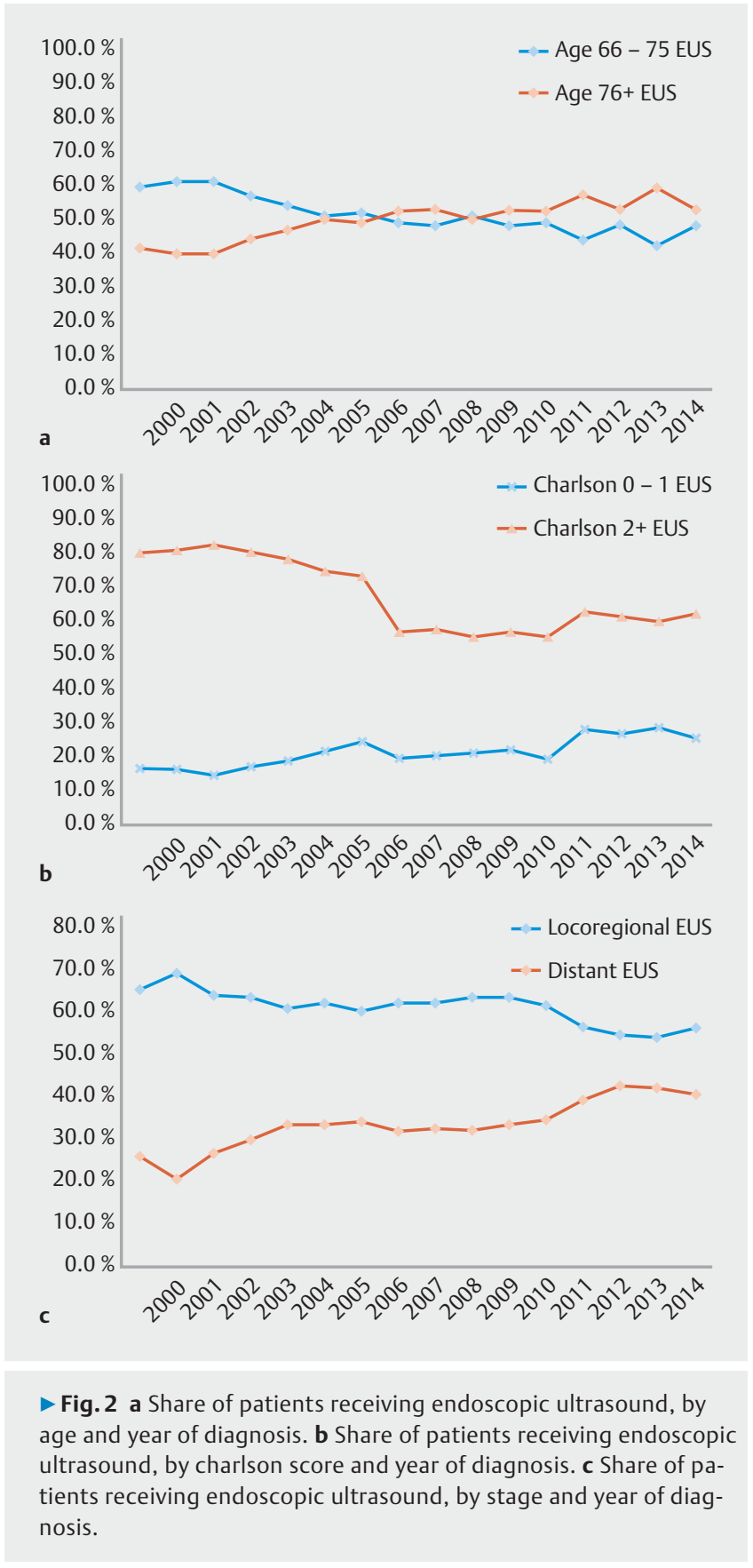

tients underwent EUS who did not also undergo those other therapies.

\section{Clinical factors of receipt of EUS}

Next, we performed multivariable analysis of factors associated with receipt of EUS. Sociodemographic factors including age, marital status, year of diagnosis, region of the country, and zip code, income level remained significant. Older patients were less likely to receive EUS ( $>$ Table 2, odds ratio [OR] 0.78, $95 \%$ confidence interval $[\mathrm{Cl}] 0.74-0.83)$, as were not married patients (OR 0.86, $95 \% \mathrm{Cl} 0.81-0.91$ ). Patients diagnosed later in the study period were significantly more likely to receive EUS compared to the first time period (2004-2007 OR 2.36, $95 \%$
Cl 2.17-2.57; 2008-2011 OR 4.27, 95\% Cl 3.92-4.65; 20122015 OR 5.14, $95 \% \mathrm{Cl} 4.72-5.60)$. Compared to those living in the Southeast United States, those living in the Northeast, Midwest, and West Coast were more likely to receive EUS (NE OR 1.31, 95\% Cl 1.20-1.44; MW OR 1.47, $95 \%$ Cl 1.24-1.50; West Coast OR $1.44,95 \% \mathrm{Cl} 1.33-1.55)$. Patients who lived in higherincome zip codes were also more likely to undergo the procedure (OR 1.17, $95 \% \mathrm{Cl}$ 1.09-1.25). Patient sex, race, living in a metropolitan area, education level of the zip code, and Charlson comorbidity score were not associated with receipt of EUS.

Patients with regional disease were more likely to receive EUS than those with localized disease (OR 1.37, 95\% Cl 1.251.50). In contrast, patients with distant disease were less likely to receive EUS than those with local disease (OR $0.43,95 \% \mathrm{Cl}$ 0.40-0.51).

Patients who received ERCP (OR 2.18, 95\% Cl 2.06-2.30), chemotherapy (OR 1.84, $95 \% \mathrm{Cl} 1.73-1.96)$ and radiation (OR $1.18,95 \% \mathrm{Cl} 1.10-1.27$ ) were more likely to receive EUS. However, during this period, surgery was not associated with EUS use.

\section{Survival analysis}

Univariable survival analysis as measure by Kaplan-Meier curves was evaluated in 4-year intervals. In 2000 to 2003 and 2004 to 2007, median survival improved for those who underwent EUS. Specifically, the median survival was 2 months for those who did not receive EUS ( $\triangleright$ Fig. $\mathbf{3 a}$, $\triangleright$ Fig. $\mathbf{3 b}$, $\triangleright$ Table $\mathbf{3}$ ). In contrast, the median survival for those who received EUS was significantly longer (7.0 months \pm 18.2 months $2000-2003$; 6.0 months \pm 17.1 months 2004-2007, $P<0.01$ for both). This difference narrowed later in the study period. Median survival was 2 months for those who did not receive EUS vs 7 months for those who did in 2008 to 2011 ( $\vee$ Fig. 3c, P<0.01). In the last study period, median survival for those who received EUS was 4 months and increased to 3 months for those who did not ( Fig.3d, $P=0.17$ ).

To better evaluate the impact of EUS on survival when it was more available later in the study period, we performed multivariable Cox Proportional Hazard Ratios for 2012 to 2015 only. After controlling for other factors, multivariable analysis suggests that undergoing EUS is protective against mortality (hazard ratio [HR] $0.88,95 \%$ confidence interval [Cl] $0.84-$ 0.93, $P<0.01$, Table 4). Other factors also were associated with improved survival, including female sex (HR 0.93, 95\% Cl .89-0.98) and living in the Midwest (HR 0.87, 95\% Cl 0.800.94; reference category Southeast). Patients who were older (HR 1.07, $95 \% \mathrm{Cl} 1.02-1.12$ ) or not married (HR 1.06, $95 \% \mathrm{Cl}$ 1.01-1.11) fared worse than younger or married patients, respectively.

Patients with more advanced stage at diagnosis (regional HR 1.41, 95\% Cl 1.30-1.54; distant HR 2.35, 95\% Cl 2.17-2.54) and higher Charlson comorbidity score (score $1 \mathrm{HR} 1.15,95 \%$ Cl 1.09-1.22; score 2 or higher HR 1.39, 95\% Cl 1.32-1.46) had higher risk of death than local disease or Charlson score of 0 , respectively. Receipt of other therapies, including ERCP (HR $0.86,95 \% \mathrm{Cl} 0.82-0.90)$, chemotherapy (HR $0.36,95 \% \mathrm{Cl}$ 
- Table 2 Logistic regression of receipt of EUS.

\begin{tabular}{|c|c|c|c|c|}
\hline & Odds ratio & Lower Cl & Upper CI & $P$ value \\
\hline \multicolumn{5}{|l|}{ Sex } \\
\hline Male & REF & & & NS \\
\hline Female & 0.99 & 0.93 & 1.05 & \\
\hline \multicolumn{4}{|l|}{ Age } & $<0.01$ \\
\hline $66-75$ & REF & & & \\
\hline $76+$ & 0.78 & 0.74 & 0.83 & \\
\hline \multicolumn{4}{|l|}{ Ethnicity } & NS \\
\hline White & REF & & & \\
\hline Non-White & 0.93 & 0.86 & 1.00 & \\
\hline \multicolumn{4}{|l|}{ Married } & $<0.01$ \\
\hline Yes & REF & & & \\
\hline No & 0.86 & 0.81 & 0.91 & \\
\hline \multicolumn{4}{|l|}{ Year diagnosed } & $<0.01$ \\
\hline $2000-2003$ & REF & & & \\
\hline 2004-2007 & 2.36 & 2.17 & 2.57 & \\
\hline 2008-2011 & 4.27 & 3.92 & 4.65 & \\
\hline 2012-2015 & 5.14 & 4.72 & 5.60 & \\
\hline \multicolumn{5}{|l|}{ Metro area } \\
\hline Metro & REF & & & NS \\
\hline Non-metro & 0.93 & 0.86 & 1.01 & \\
\hline \multicolumn{5}{|l|}{ Region } \\
\hline Northeast & 1.31 & 1.20 & 1.44 & $<0.01$ \\
\hline Southeast & REF & & & \\
\hline Midwest & 1.47 & 1.24 & 1.50 & $<0.01$ \\
\hline West Coast & 1.44 & 1.33 & 1.55 & $<0.01$ \\
\hline \multicolumn{4}{|l|}{ Income } & $<0.01$ \\
\hline High income & 1.17 & 1.09 & 1.25 & \\
\hline Low income & REF & & & \\
\hline \multicolumn{5}{|l|}{ Education } \\
\hline High education & 0.95 & 0.89 & 1.02 & NS \\
\hline Low education & REF & & & \\
\hline \multicolumn{5}{|c|}{ SEER historic stage } \\
\hline Local & REF & & & \\
\hline Regional & 1.37 & 1.25 & 1.50 & $<0.01$ \\
\hline Distant & 0.43 & 0.40 & 0.51 & $<0.01$ \\
\hline \multicolumn{5}{|c|}{ Charlson Comorbidity Score } \\
\hline 0 & REF & & & \\
\hline 1 & 0.98 & 0.92 & 1.05 & NS \\
\hline $2+$ & 1.01 & 0.94 & 1.08 & NS \\
\hline ERCP & 2.18 & 2.06 & 2.30 & $<0.01$ \\
\hline
\end{tabular}

- Table 2 (Continuation)

\begin{tabular}{|l|c|c|c|c|}
\hline & Odds ratio & Lower Cl & Upper CI & $P$ value \\
\hline Chemotherapy & 1.84 & 1.73 & 1.96 & $<0.01$ \\
\hline Radiation & 1.18 & 1.10 & 1.27 & $<0.01$ \\
\hline Surgery & 0.94 & 0.87 & 1.02 & NS \\
\hline
\end{tabular}

EUS, endoscopic ultrasound; $\mathrm{Cl}$, confidence interval; REF, reference category; SEER, Surveillance, Epidemiology and End Results; ERCP, endoscopic retrograde cholangiopancreatography; NS, not significant.

$0.35-0.38$ ), radiation (HR $0.72,95 \% \mathrm{Cl} 0.67-0.77$ ) and surgery (HR 0.40, $95 \% \mathrm{Cl} 0.37-0.44$ ) were protective.

These analyses were repeated after stratification by stage ( $\triangleright$ Table 5, - Table 6, > Table 7). For local and distant disease, receipt of EUS remained protective (local HR $0.86,95 \% \mathrm{Cl}$ 0.75-0.99; distant HR 0.79, $95 \% \mathrm{Cl} 0.73-0.84)$. In contrast, for regional disease receipt of EUS was not associated with survival benefit (HR 1.12, $95 \% \mathrm{Cl} 1.02-1.24)$.

\section{Discussion}

This study describes the increased use of EUS over time, including among patients with older age, higher Charlson comorbidity scores, more advanced stage disease, and even among those who ultimately did not undergo cancer-directed therapy. Previous studies have suggested that undergoing EUS is associated with improved survival; however, the studies were performed before EUS was widely available in the community and incorporated in guidelines $[2,4,19]$. To our knowledge, this is the first study to describe increased use over time for all patients with $P C$, including among patients with more comorbid conditions, advanced age, and advanced disease. Furthermore, this study demonstrates that the survival benefit was attenuated over time. This was especially notable in patients with regional disease after controlling for other factors, whose treatment plan may be most impacted by appropriate staging. We hypothesize that as EUS became increasingly available, it became less of a signal of treatment at an expert center and of selected patient factors. This is reflected in the change in guidelines from the ASGE to recommend EUS rather than ERCP for evaluation of pancreatic neoplasia, reflecting evidence that emerged over the time period suggesting improved sensitivity and specificity of EUS as well as its capacity to obtain specimens for diagnosis [2].

There are a number of reasons that could explain the survival benefit suggested in other studies. Patients who undergo EUS: (1) may be more likely to engage in care and treatment options; (2) receive more stage appropriate care; or (3) may be selected for the procedure based on clinical factors that could not be controlled for in this retrospective study. For example, receipt of EUS may signal care at an expert center, who care for a higher number of patients and offer clinical trials leading to better outcomes. The survival benefit of EUS for patients with both local and distant disease suggests that undergoing EUS allowed them to receive more stage-appropriate care. Because of its 

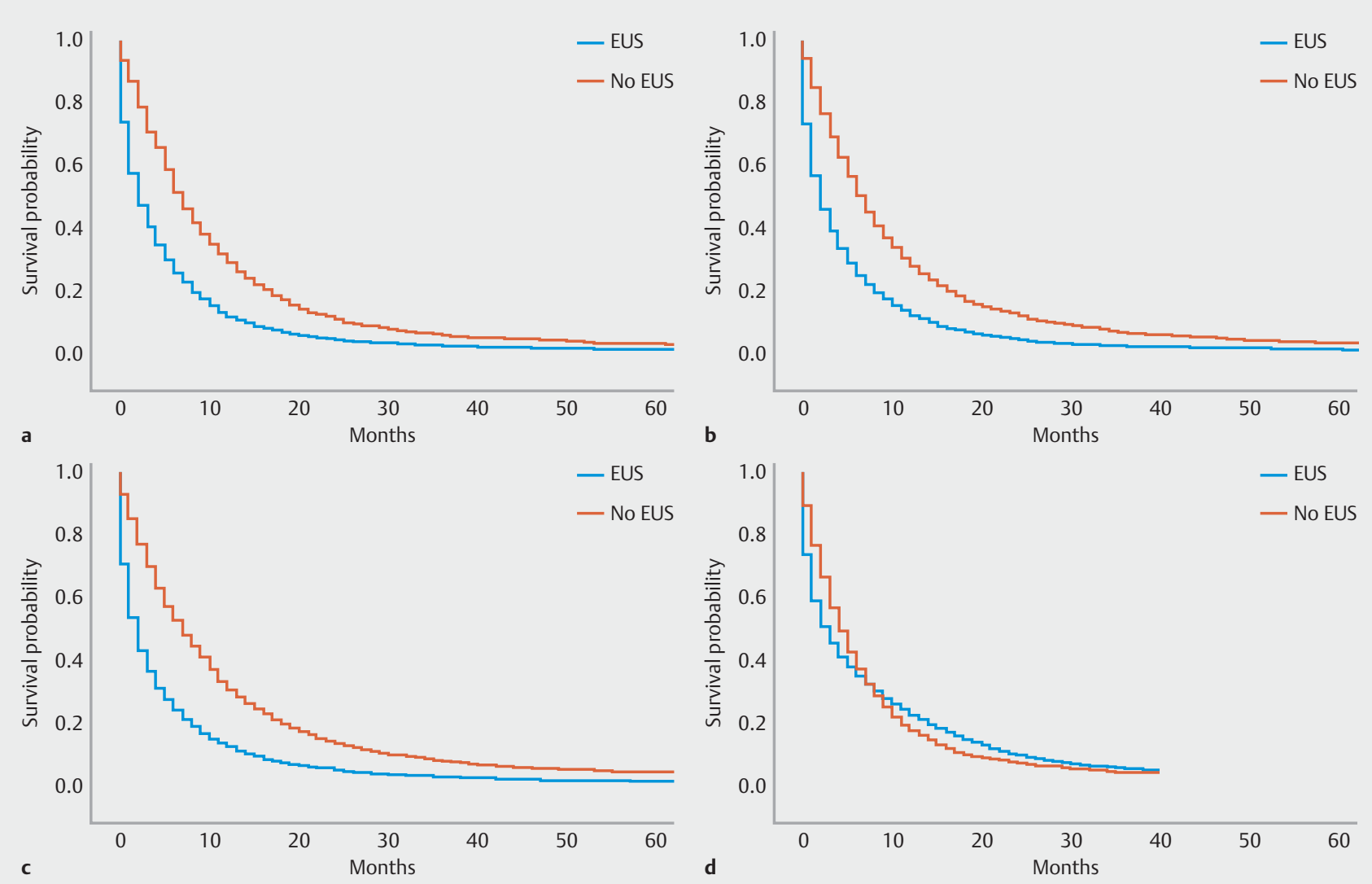

Fig. 3 Kaplan-Meier curve for pancreatic cancer patients survival, by receipt of endoscopic ultrasound. a Years 2000 to 2003 . b Years 2004 to 2007. c Years 2008 to 2011. d Years 2012 to 2015.

- Table 3 Median survival, by year of diagnosis and receipt of endoscopic ultrasound.

\begin{tabular}{|l|l|l|l|l|l|}
\hline & No EUS & & EUS & \\
\hline & Median survival (months) & SD & Median Survival (months) & SD & Log-rank $\boldsymbol{P}$ value \\
\hline $2000-2003$ & 2 & 13.3 & 7 & 18.2 & $<0.01$ \\
\hline $2004-2007$ & 2 & 11.9 & 6 & 17.1 & $<0.01$ \\
\hline $2008-2011$ & 2 & 11.8 & 7 & 16.7 & $<0.01$ \\
\hline $2012-2015$ & 3 & 9.8 & 4 & 8 & 0.17 \\
\hline
\end{tabular}

EUS, endoscopic ultrasound; SD, standard deviation.

sensitivity compared to other modalities, the stage at diagnosis for patients who underwent EUS may have been more accurate than had it been based on other modalities. For example, patients with subtle lesions not identifiable on imaging who underwent EUS may have had stage increased from locally resectable to regional disease, and then been included in the regional disease group. This could have important impacts on therapy. Although neoadjuvant chemotherapy was not widely used in the time period of this study, it has been shown to have promise and appropriate staging prior to surgery is an important part of this protocol [20-24]. Furthermore, if EUS itself had a survival benefit, given the increase in use, it is plausible that survival would improve over time. However that was not the case in this study or others [1]. As EUS became increasingly available and procedural volume increased, it is possible that providers became more comfortable performing this procedure in patients who may not have received it earlier in the study period because of patient or other clinical factors.

This study has several limitations. It was retrospective; therefore, it is not known why some patients underwent EUS whereas others did not. We addressed this with multivariable analysis but the possibility remains that some factors that cannot be measured, such as care at an expert center, still confound the analysis. Furthermore, treatment algorithms chan- 
- Table 4 Cox proportional hazard ratios, all stages, years 2012 to 2015.

\begin{tabular}{|c|c|c|c|c|}
\hline & Hazard ratio & Lower Cl & Upper CI & $P$ value \\
\hline No EUS & REF & & & \\
\hline EUS & 0.88 & 0.84 & 0.93 & $<0.01$ \\
\hline \multicolumn{5}{|l|}{ Sex } \\
\hline - Male & REF & & & \\
\hline - Female & 0.93 & 0.89 & 0.98 & $<0.01$ \\
\hline \multicolumn{5}{|l|}{ Age } \\
\hline . $66-75$ & REF & & & \\
\hline . $76+$ & 1.07 & 1.02 & 1.12 & $<0.01$ \\
\hline \multicolumn{5}{|l|}{ Ethnicity } \\
\hline - White & REF & & & \\
\hline - Non-White & 0.97 & 0.91 & 1.03 & 0.35 \\
\hline \multicolumn{5}{|l|}{ Married } \\
\hline - Yes & REF & & & \\
\hline - No & 1.06 & 1.01 & 1.11 & 0.02 \\
\hline \multicolumn{5}{|l|}{ Metro area } \\
\hline - Metro & REF & & & \\
\hline - Non-metro & 0.99 & 0.93 & 1.06 & 0.84 \\
\hline \multicolumn{5}{|l|}{ Region } \\
\hline - Northeast & 0.98 & 0.91 & 1.05 & 0.51 \\
\hline - Southeast & REF & & & \\
\hline - Midwest & 0.87 & 0.80 & 0.94 & $<0.01$ \\
\hline - West coast & 0.98 & 0.93 & 1.05 & 0.59 \\
\hline \multicolumn{5}{|l|}{ Income } \\
\hline - High income & 0.97 & 0.91 & 1.02 & 0.26 \\
\hline - Low income & REF & & & \\
\hline \multicolumn{5}{|l|}{ Education } \\
\hline - High education & 1.01 & 0.95 & 1.07 & 0.81 \\
\hline - Low education & REF & & & \\
\hline \multicolumn{5}{|l|}{ SEER historic stage } \\
\hline - Local & REF & & & \\
\hline - Regional & 1.41 & 1.30 & 1.54 & $<0.01$ \\
\hline - Distant & 2.35 & 2.17 & 2.54 & $<0.01$ \\
\hline \multicolumn{5}{|c|}{ Charlson Comorbidity Score } \\
\hline . 0 & REF & & & \\
\hline . 1 & 1.15 & 1.09 & 1.22 & $<0.01$ \\
\hline . $2+$ & 1.39 & 1.32 & 1.46 & $<0.01$ \\
\hline ERCP & 0.86 & 0.82 & 0.90 & $<0.01$ \\
\hline Chemotherapy & 0.36 & 0.35 & 0.38 & $<0.01$ \\
\hline Radiation & 0.72 & 0.67 & 0.77 & $<0.01$ \\
\hline Surgery & 0.40 & 0.37 & 0.44 & $<0.01$ \\
\hline
\end{tabular}

$\mathrm{Cl}$, confidence interval; REF, reference category; NS, not significant; SEER, Surveillance, Epidemiology and End Results; ERCP, endoscopic retrograde cholangiopancreatography. 
Table 5 Cox proportional hazard ratios, local stage, years 2012 to 2015.

\begin{tabular}{|c|c|c|c|c|}
\hline & HR & $95 \% \mathrm{Cl}$ & & $P$ value \\
\hline No EUS & REF & & & \\
\hline EUS & 0.86 & 0.75 & 0.99 & 0.04 \\
\hline \multicolumn{5}{|l|}{ Sex } \\
\hline - Male & REF & & & \\
\hline - Female & 0.92 & 0.79 & 1.08 & 0.3 \\
\hline \multicolumn{5}{|l|}{ Age } \\
\hline - 66-75 & REF & & & \\
\hline . $76+$ & 1.05 & 0.88 & 1.25 & 0.58 \\
\hline \multicolumn{5}{|l|}{ Ethnicity } \\
\hline - White & REF & & & \\
\hline - Non-White & 0.96 & 0.79 & 1.16 & 0.66 \\
\hline \multicolumn{5}{|l|}{ Married } \\
\hline - Yes & REF & & & \\
\hline - No & 1.10 & 0.94 & 1.28 & 0.24 \\
\hline
\end{tabular}

Metro area

\begin{tabular}{|l|l|l|l|l|}
\hline - Metro & REF & & & \\
\hline - Non-metro & 1.01 & 0.83 & 1.23 & 0.95 \\
\hline
\end{tabular}

Region

- Northeast

0.95

0.74

\begin{tabular}{l}
$1.21 \quad 0.66$ \\
\hline
\end{tabular}

- Southeast

REF

- Midwest

0.99

- West coast

\begin{tabular}{l}
1.08 \\
\hline
\end{tabular}

$1.25 \quad 0.95$

1.08

0.89

$1.31 \quad 0.43$

Income

- High income

1.10

0.91

1.32

- Low income

REF

Education

0.57

\begin{tabular}{|l|l|l|l|}
\hline - High education & 1.05 & 0.88 & 1.26 \\
\hline - Low education & REF & & \\
\hline
\end{tabular}

Charlson Comorbidity Score

\begin{tabular}{|l|l|l|l|l|}
\hline \multicolumn{1}{|l|}{0} & REF & & & \\
\hline \hline 1 & 1.44 & 1.20 & 1.73 & $<0.01$ \\
\hline - $2+$ & 1.78 & 1.51 & 2.11 & $<0.01$ \\
\hline ERCP & 0.99 & 0.85 & 1.14 & 0.84 \\
\hline Chemotherapy & 0.58 & 0.49 & 0.69 & $<0.01$ \\
\hline Radiation & 0.81 & 0.66 & 0.99 & 0.04 \\
\hline Surgery & 0.25 & 0.18 & 0.34 & $<0.01$ \\
\hline
\end{tabular}

$\mathrm{Cl}$, confidence interval; REF, reference category; NS, not significant.
- Table 6 Cox proportional hazard ratios, regional stage, years 2012 to 2015 .

\begin{tabular}{|l|l|l|l|l|}
\hline & HR & $\mathbf{9 5} \mathbf{C l}$ & & P value \\
\hline No EUS & REF & & & \\
\hline EUS & 1.12 & 1.02 & 1.24 & 0.02 \\
\hline Sex & & & & \\
\hline - Male & REF & & & \\
\hline - Female & 1.05 & 0.95 & 1.16 & 0.34 \\
\hline
\end{tabular}

Age

- $66-75$

REF

$.76+$

1.07

0.97

1.18

0.19

Ethnicity

- White

- Non-White

REF

1.

0.97

\begin{tabular}{l|l|}
1.24 & 0.15
\end{tabular}

Married

- Yes

REF

- No

0.99

0.9

\begin{tabular}{l|l}
1.1 & 0.89
\end{tabular}

Metro area

- Metro

- Non-metro

REF

1.01

0.87

\begin{tabular}{ll|l}
1.16 & 0.94
\end{tabular}

Region

- Northeast

0.91

0.78

$\begin{array}{ll}1.06 & 0.21\end{array}$

- Southeast

REF

- Midwest

- West Coast

\begin{tabular}{l|l|}
$0.76 \quad 0.64$ \\
\hline
\end{tabular}

$0.9<0.01$

\begin{tabular}{l|l}
$0.94 \quad 0.83$
\end{tabular}

\begin{tabular}{|l|l|}
\hline 1.06 & 0.31
\end{tabular}

Income

- High income

0.9

0.85

\begin{tabular}{ll}
$1.07 \quad 0.4$ \\
\hline
\end{tabular}

- Low income

REF

Education

- High education

1.03

0.91

$\begin{array}{ll}1.16 & 0.68\end{array}$

- Low education

REF

Charlson Comorbidity Score

\begin{tabular}{l|l} 
- 0 & REF
\end{tabular}

- 1

- $2+$

1.18

18

1.05

\begin{tabular}{|l|l|}
\hline 1.35 & 1.21
\end{tabular}

$1.32<0.01$

ERCP

Chemotherapy

\begin{tabular}{l|l}
1.04 & 0.95
\end{tabular}

\begin{tabular}{l|l}
0.39 & 0.35
\end{tabular}

$1.52<0.01$

Radiation

Surgery

0.6

0.35

\begin{tabular}{l|l}
1.14 & 0.43
\end{tabular}

$\mathrm{Cl}$, confidence interval; REF, reference category; NS, not significant; ERCP, endoscopic retrograde cholangiopancreatography. 
- Table 7 Cox proportional hazard ratios, distant stage, years 2012 to 2015 .

\begin{tabular}{|c|c|c|c|c|}
\hline & HR & $95 \% \mathrm{Cl}$ & & $P$ value \\
\hline No EUS & REF & & & \\
\hline EUS & 0.79 & 0.73 & 0.84 & $<0.01$ \\
\hline \multicolumn{5}{|l|}{ Sex } \\
\hline - Male & REF & & & \\
\hline - Female & 0.91 & 0.85 & 0.97 & $<0.01$ \\
\hline \multicolumn{5}{|l|}{ Age } \\
\hline . $66-75$ & REF & & & \\
\hline . $76+$ & 1.06 & 0.99 & 1.12 & 0.09 \\
\hline \multicolumn{5}{|l|}{ Ethnicity } \\
\hline - White & REF & & & \\
\hline - Non-White & 0.93 & 0.86 & 1.01 & 0.09 \\
\hline \multicolumn{5}{|l|}{ Married } \\
\hline - Yes & REF & & & \\
\hline - No & 1.07 & 1.00 & 1.14 & 0.04 \\
\hline \multicolumn{4}{|l|}{ Metro area } & 0.48 \\
\hline - Metro & REF & & & \\
\hline - Non-metro & 0.97 & 0.89 & 1.06 & \\
\hline \multicolumn{5}{|l|}{ Region } \\
\hline - Northeast & 1.01 & 0.91 & 1.11 & 0.89 \\
\hline - Southeast & REF & & & \\
\hline - Midwest & 0.8 & 0.72 & 0.89 & $<0.01$ \\
\hline - West coast & 0.97 & 0.90 & 1.05 & 0.49 \\
\hline \multicolumn{4}{|l|}{ Income } & 0.01 \\
\hline - High income & 0.91 & 0.85 & 0.98 & \\
\hline - Low income & REF & & & \\
\hline \multicolumn{4}{|l|}{ Education } & 0.6 \\
\hline - High education & 0.98 & 0.91 & 1.06 & \\
\hline - Low education & REF & & & \\
\hline
\end{tabular}

Charlson Comorbidity Score

\begin{tabular}{|l|l|l|l|l|}
\hline " 0 & REF & & & \\
\hline " 1 & 1.1 & 1.02 & 1.18 & 0.01 \\
\hline " $2+$ & 1.33 & 1.24 & 1.43 & $<0.01$ \\
\hline ERCP & 0.79 & 0.74 & 0.85 & $<0.01$ \\
\hline Chemotherapy & 0.31 & 0.28 & 0.33 & $<0.01$ \\
\hline Radiation & 0.70 & 0.63 & 0.78 & $<0.01$ \\
\hline Surgery & 0.33 & 0.27 & 0.39 & $<0.01$ \\
\hline
\end{tabular}

$\mathrm{Cl}$, confidence interval; REF, reference category; NS, not significant; ERCP, endoscopic retrograde cholangiopancreatography. ged, including, for example, as described above with increasing use of neoadjuvant chemotherapy. Second, as with any claims database, the accuracy of the data are limited to the claims submitted by health care providers. However, studies suggest that accuracy of procedure coding is very good $[25,26]$. Also, treatment practices may have changed during this time period, which may have led to changes in use of EUS, other therapies, and outcomes for those patients. Certain important clinical factors, such as tobacco use or serologic markers, are not included in SEER-Medicare and, therefore, could not be included in this analysis. While Medicare claims data can be queried for ICD-10 codes (e. g. tobacco use disorder), the sensitivity of this method is poor and is not recommended [27]. Finally, because this study used Medicare claims, the population was older and included more women than the general population with $P C$ in the United States [1]. It is possible that our findings are not generalizable to a population $<65$ years of age, or that inclusion of younger patients may alter the results of this study.

\section{Conclusions}

In conclusion, this study reevaluated findings from previous studies showing that EUS was associated with survival benefit in patients diagnosed with PC. We found that the story was more complex: As EUS use increased overall and in a more diverse patient population, the survival benefit was attenuated over time. This suggests that EUS may have been a marker of access to other treatments. Further studies to better understand barriers to access to care are needed, especially for such a lethal disease.

\section{Competing interests}

NAK serves as a consultant for Apollo Endosurgery, Boston Scientific, Intuitive surgical, and Olympus. CJD has the following disclosures: Boston Scientific: consulting/speaking, AbbVie: speaking, Covidien: consulting/speaking, STERIS: speaking, Mauna Kea: speaking, SafeHeal: consulting. The remaining authors have no conflicts to declare.

References

[1] Siegel RL, Miller KD, Jemal A. Cancer statistics, 2020. CA Can J Clin 2020; 70: 7-30

[2] Eloubeidi MA et al. The role of endoscopy in the evaluation and management of patients with solid pancreatic neoplasia. Gastrointest Endosc 2016; 83: 17-28

[3] Tempero MA et al. Pancreatic Adenocarcinoma, version 2.2012: featured updates to the NCCN Guidelines. . J Natl Compr Canc Netw 2012; 10: 703-713

[4] Ngamruengphong $S$ et al. EUS and survival in patients with pancreatic cancer: a population-based study. Gastrointest Endosc 2010; 72: 7883, 83.e1-2

[5] Rustgi SD et al. Age, socioeconomic features, and clinical factors predict receipt of endoscopic retrograde cholangiopancreatography in pancreatic cancer. World J Gastrointest Endosc 2019; 11: 133-144 
[6] Shapiro $\mathrm{M}$ et al. Associations of socioeconomic variables with resection, stage, and survival in patients with early-stage pancreatic cancer. JAMA Surg 2016; 151: 338-345

[7] Zeng C et al. Disparities by Race, Age, and sex in the improvement of survival for major cancers: results from the National Cancer Institute Surveillance, Epidemiology, and End Results (SEER) program in the United States, 1990 to 2010. JAMA Oncol 2015; 1: 88-96

[8] Schmocker RK et al. Utilization of preoperative endoscopic ultrasound for pancreatic adenocarcinoma. HPB 2017; 19: 465-472

[9] Adler DG et al. ASGE guideline: the role of ERCP in diseases of the biliary tract and the pancreas. Gastrointest Endosc 2005; 62: 1-8

[10] National Cancer Institute. Overview of the SEER Program. June 23, 2017. http://seer.cancer.gov/about/overview.htm

[11] Amin S et al. Metformin Improves survival in patients with pancreatic ductal adenocarcinoma and pre-existing diabetes: a propensity score analysis. Am J Gastroenterol 2016; 111: 1350-1357

[12] Klabunde CN, Harlan LC, Warren JL. Data sources for measuring comorbidity: a comparison of hospital records and medicare claims for cancer patients. Med Care 2006; 44: 921-928

[13] Charlson ME et al. A new method of classifying prognostic comorbidity in longitudinal studies: development and validation. J Chronic Dis 1987; 40: 373-383

[14] Deyo RA, Cherkin DC, Ciol MA. Adapting a clinical comorbidity index for use with ICD-9-CM administrative databases. J Clin Epidemiol 1992; 45: 613-619

[15] Klabunde CN et al. Development of a comorbidity index using physician claims data. J Clin Epidemiol 2000; 53: 1258-1267

[16] Ruhl JL, Hurlbut CC, Ries LAG et al. Summary Stage 2018: Codes and Coding Instructions. Bethesda, MD: National Cancer Institute; 2018

[17] Young JL Jr, Roffers SD, Ries LAG et al. SEER Summary Staging Manual - 2000: Codes and Coding Instructions. Bethesda, MD: National Cancer Institute; 2001: NIH Pub. No. 01-4969
[18] Saleh MMA et al. Preoperative endoscopic stent placement before pancreaticoduodenectomy: A meta-analysis of the effect on morbidity and mortality. Gastrointest Endosc 2002; 56: 529-534

[19] Parmar AD et al. Evaluating comparative effectiveness with observational data: endoscopic ultrasound and survival in pancreatic cancer. Cancer 2013; 119: 3861-3869

[20] de Geus SW et al. Neoadjuvant therapy versus upfront surgery for resected pancreatic adenocarcinoma: A nationwide propensity score matched analysis. Surgery 2017; 161: 592-601

[21] Evans DB et al. Preoperative gemcitabine-based chemoradiation for patients with resectable adenocarcinoma of the pancreatic head. J Clin Oncol 2008; 26: 3496-3502

[22] Itchins $M$ et al. Retrospective cohort analysis of neoadjuvant treatment and survival in resectable and borderline resectable pancreatic ductal adenocarcinoma in a high volume referral centre. Eur J Surg Oncol 2017; 43: 1711-1717

[23] Shrestha B et al. Long-term survival benefit of upfront chemotherapy in patients with newly diagnosed borderline resectable pancreatic cancer. Cancer Med 2017; 6: 1552-1562

[24] Zhan HX, Xu JW, Wu D et al. Neoadjuvant therapy in pancreatic cancer: a systematic review and meta-analysis of prospective studies. Cancer Med 2017; 16: 1201-1219

[25] Cooper GS et al. Use of SEER-Medicare data for measuring cancer surgery. Med Care 2002; 40: IV-43-8 doi:10.1097/01. mlr.0000020943.21850.f1

[26] Cooper GS et al. The utility of Medicare claims data for measuring cancer stage. Med Care 1999; 37: 706-711

[27] National Cancer Institute. Measures that are limited or not available in the data. April 30, 2021. https://healthcaredelivery.cancer.gov/seermedicare/considerations/measures.html 